\title{
Achieving acid sites accessibility and pore compatibility in MWW nanosheets for alkylation of benzene with 1-dodecene
}

\author{
Baoyu Liu ${ }^{1}$, Zhantu Liao ${ }^{1}$, Jianwen Zhang ${ }^{1}$, and Yeqing Huang ${ }^{2}$ \\ ${ }^{1}$ Affiliation not available \\ ${ }^{2}$ Guangdong University of Technology - University Town Campus
}

December 22, 2021

\begin{abstract}
Regularly spaced MWW nanosheets combined with single-unit-cell thickness and optimized Al species distribution are highly effective for the alkylation between benzene with 1-dodecene, high conversion of 1-dodecene (ca. $85 \%$ ) and selectivity of 2-LAB (ca. $80 \%$ ) can be obtained. Detailed studies of this MWW nanaosheets system reveal that ultra-thin MWW nanosheets with ordered arrangement can expose more accessible Brønsted acid sites (ca. $89 \%$ ), and specially place framework $\mathrm{Al}$ species on the T2 sites (ca. $\sim 13 \%$ ), in which the alkylation mainly occurred under the catalysis of accessible Brønsted acid sites. Besides, the desired 2-LAB is produced on the unique 12-MR hemicavities with solid binding energy and perfect steric configuration. As a proof-of-concept study, we integrate the highly exposed Brønsted acid sites and unrivalled shape-selectivity in the regularly spaced MWW nanosheets system with well characterized acid sites accessibility and pore adaptability, leading to the excellent catalytic performance.
\end{abstract}

\section{Introduction}

Long chain linear alkylbenzene $(\mathrm{LAB})$ is one of critical chemicals since its sulphonated products are the raw materials for industrial and domestical detergents. ${ }^{1}$ Commercially, the LAB is produced through the alkylation between benzene with $\alpha$-olefins $\left(\mathrm{C}_{8}-\mathrm{C}_{16}\right)$, which is catalyzed under the $\mathrm{HF}$ and $\mathrm{AlCl}_{3}$ system. ${ }^{2}$ Notability, the position of phenyl group in long chain $\alpha$-olefin is crucial to biodegradability and solubility, among various LAB isomers, the 2 -LAB is the most biodegradable and possesses the best solubility. ${ }^{3}$ Therefore, it's highly desired to develop an efficiency catalysis technology to improve the selectivity of 2-LAB isomer. However, the traditional $\mathrm{HF}$ and $\mathrm{AlCl}_{3}$ catalysis technology for the production of $\mathrm{LAB}$ brings some severe issues: 1) these homogeneous catalysts can generate a large number of waste acids during the producing process, they also cause serious corrosion towards reactor, and the separation with the reactants and products is a tough energy-consuming process. ${ }^{4}$ In addition, the HF requires special handling and equipment, which further increase cost and risk; 2) $\mathrm{HF}$ and $\mathrm{AlCl}_{3}$ catalysts exhibit low 2-LAB selectivity with $15 \%$ and $30 \%,{ }^{5}$ respectively. This is far from the target that develops an environmental-friendly, noncorrosive, reusable and green alkylation technology with desired 2-LAB selectivity.

To overcome these problems, a large number of clean technology has been investigated based on the solid acid catalysts such as zeolites, ${ }^{6,7}$ ion exchange resin, ${ }^{8}$ metal oxides, ${ }^{2}$ clay ${ }^{9}$ and heteropoly acid. ${ }^{10}$ Among them, the UOP company firstly realized the production of LAB in the industrial scale based on the Detal technology by employing $\mathrm{HF}$ or $\mathrm{NH}_{4} \mathrm{~F}$ modified $\mathrm{SiO}_{2}-\mathrm{Al}_{2} \mathrm{O}_{3}$ as the solid catalyst, ${ }^{11}$ which open a window for the development of green alkylation technology between benzene with long chain $\alpha$-olefins. Currently, the production of $\mathrm{LAB}$ mainly depends on the $\mathrm{HF}, \mathrm{AlCl}_{3}$ and Detal technology, and the corresponding market share is $75 \%, 10 \%$ and $15 \%$, respectively. Unsatisfactorily, the selectivity of 2-LAB is only increased to $25 \%$ through Detal technology. ${ }^{12}$ Besides, the acid strength of $\mathrm{HF}$ or $\mathrm{NH}_{4} \mathrm{~F}$ modified $\mathrm{SiO}_{2}-\mathrm{Al}_{2} \mathrm{O}_{3}$ is not enough to catalyze the alkylation of benzene with long chain $\alpha$-olefins, and the reaction must be operated 
under the high temperature and pressure, resulting in high cost compared with conventional HF technology. Therefore, it's still highly expected to obtain an efficient green technology for the production of 2-LAB.

Zeolites is a class of widely used solid catalysts with tunable acidity and pore size, which is an ideal candidate for alkylation between benzene with long chain linear $\alpha$-olefins. In the past decades, great efforts have been made to search suitable zeolites for 2-LAB synthesis. ${ }^{13}$ The major issues that prevent the successful industrialization of zeolite catalysts for LAB process are the non-ideal distribution of LAB isomers and deactivation of zeolites. ${ }^{6}$ On the one hand, the activity of zeolites is from acid sites that can catalyze alkylation between benzene and $\alpha$-olefins. Thus, zeolites must expose more accessible acid sites in order to improve activity, the effective strategy for improving accessible acid sites in zeolite framework is fabrication of mesopore zeolites with open hierarchical channels. The mesopores not only improve the accessibility of acid sites, but also enhance the diffusion of coke precursor and increase the life time of catalysts. On the other hand, the shape-selective catalysis for zeolites is mainly based on the size or shape in sterically confined environments. ${ }^{14}$ If the mesopores are introduced into the framework or special fabrication of layer zeolites with ultra-thin thickness along one crystal axis, the shape-selective effect of zeolites is lineally decreased. Therefore, it's still a huge challenge to fabricate suitable zeolite catalysts for the production of 2-LAB.

In present research, the structure of MWW zeolite are optimized to solve the above-mentioned issues. Dual template strategy with conventional hexamethyleneimine (HMI) structure directing agent and long chain quaternary ammonium surfactant is employed to delaminate the MWW zeolites, which expect to expose the external acid sites and improve the accessibility of acid sites. Our finds confirm that external surface Brønsted acid sites can be systematically tailored by tuning the hydrophobic chain length of surfactant. Moreover, the mono-layer delaminated MWW zeolite is obtained by increasing the ratio between quaternary ammonium surfactant and HMI. Computational results reveals that the external isolated 12-ring hemicavities located on the upper and lower surface of the MWW lamella can stabilize the 2-LAB due to the most appropriate sterical configuration and highest binding energy with 12-ring hemicavities, which is benefit to the formation of 2-LAB. Our study shows that a regularly spaced MWW zeolite nanosheets system can greatly improve the activity of catalysts in the alkylation between benzene with 1-dodecene without sacrificing the selectivity of 2-LAB. In addition, the catalytic performance of MWW zeolite nanosheets are further maximized by altering the distribution of $\mathrm{Al}$ species on the exterior surfaces and inhibiting the stacking of MWW zeolite layers, the optimized MWW zeolite layers also show a superior stability with robust selectivity of 2-LAB, which is highly desired and expected as an ideal solid catalyst for the industrial production of 2-LAB.

\section{Experimental section}

\section{Catalyst preparation}

The MWW zeolite nanosheets were prepared by employing the dual template strategy following the previous report, ${ }^{15}$ and regularly spaced MWW zeolite nanosheets were fabricated according to the method developed by Tsapatsis et al. ${ }^{16}$ The detailed synthesis produces and characteristic technology can be found in the experimental procedures section in supporting information.

Computational Results

The calculations in this work were performed using Forcite module in Materials Studio. ${ }^{17}$ To calculated the interaction energy between LAB isomers and zeolite, we first build a cleaved model with the bowl shape structure exposed on the surface to provide effective adsorption space. This model was optimized with energy, force, displacement convergence thresholds set to $1 \times 10^{-4} \mathrm{kcal} / \mathrm{mol}, 5 \times 10^{-3} \mathrm{kcal} / \mathrm{mol} / \AA$ and $5 \times 10^{-3} \AA$, respectively. The van der Waals interaction between the atoms was modeled using universal force field, while the electrostatic interaction was described with atomic partial charges calculated using QEq method and summed with Ewald method. The van der Waals interaction was truncated within a cutoff distance of $15.5 \AA$, and the Ewald accuracy for computing electrostatic interaction was set to $1 \times 10^{-4}$ $\mathrm{kcal} / \mathrm{mol}$. After the optimization, one molecule of the LAB isomers was respectively adsorbed in the bowl shape structure of the model as an adsorbed configuration. These configurations were sequentially optimized with the same parameters as optimizing the bare model. Finally, using the same parameters to describe van 
der Waals interaction and electrostatic interaction, we calculated the single point energy of these adsorbed configurations, the bare adsorbent model and the LAB isomers, and obtained the binding energy using Eq.1,

$\mathrm{E}_{\text {binding }}=\mathrm{E}_{\text {configuration }}-\mathrm{E}_{\text {bare model }}-\mathrm{E}_{\mathrm{LAB}}(1)$

Catalytic property

The liquid alkylation between benzene and 1-dodecene was performed in a three-necked round-bottom flask equipped with condensation under stirring condition. Prior to measurement, the resultant zeolite samples were ion exchanged three time with $1 \mathrm{M} \mathrm{NH}_{4} \mathrm{NO}_{3}$ solution at $80^{\circ} \mathrm{C}$ for $12 \mathrm{~h}$, and benzene, 1-dodecene with ethyl cyclohexane was dried over $4 \mathrm{~A}$ zeolite for $12 \mathrm{~h}$. In a typical experiment, $0.1 \mathrm{~g}$ zeolite catalyst, 112 mmol benzene and $7.2 \mathrm{mmol}$ ethyl cyclohexane was added into the flask, then the flask was stirred at $80^{\circ} \mathrm{C}$ for $0.5 \mathrm{~h}$, subsequently $12.8 \mathrm{mmol}$ 1-dodecene was added. This moment was marked as the initial reaction time. Liquid samples were withdrawn and analyzed by a gas chromatograph (Agilent $7890 \mathrm{~A}$ ) equipped with a polyorganosiloxane capillary column (HP-5, $30.0 \mathrm{~m} \times 0.32 \mathrm{~mm}, 0.25 \mu \mathrm{m})$ connected to a flame ionization detector (FID). For the recycling experiment, zeolites after cycle were filtered and dried at 120 for $12 \mathrm{~h}$, then they were reused to evaluate the catalytic performance in next cycle without further treatment.

Results and discussion

Synthesis of MWW zeolite nanosheets

The dual template synthesis strategy with HMI and long chain quaternary ammonium surfactant was used to delaminate the MWW zeolites, which can expect to generate MWW zeolite nanosheets and expose more exterior Brønsted acid sites for alkylation. It was reported that cetyltrimethylammonium bromide (CTAB) could act as a positive counterion role to balance negative charge of framework $\mathrm{Al}$ atoms at surface sites on the MWW zeolite lamellas in the zeolite synthesis gel, ${ }^{15}$ the accumulation of long chain quaternary ammonium surfactants on exterior surfaces can impede layer-layer interactions owing to the tangling effect of long hydrophobic tail of surfactant, resulting in the separation between MWW layers. Herein, the long chain quaternary ammonium surfactants with different tails such as dodecyl trimethylammonium bromide (DTAB), myristyltrimethylammonium bromide (MTAB) and cetyltrimethylammonium bromide (CTAB) were employed to tune the degree of delaminated MWW nanosheets based on discrepant long tails that can generate the various tangling effect due to the steric hindrance. ${ }^{18}$ In addition, the excess surfactant was added into synthesis gel to ensure that the sufficient coverage of incorporated surfactant on the exterior surface of MWW layers was achieved in order to effectively impede layer alignment.

Fig. 1 gave the result of powder x-ray diffraction (PXRD) patterns of multiple-layer and mono-layer MWW zeolite nanosheets, which was commonly used to evaluate the arrangement of MWW layers in the $2 \vartheta$ range of 6-10@. ${ }^{19}$ As shown in Fig. 1, MCM-22 presented three peaks at $7.2 @, 8.0 @$ and 10.0@, corresponding (100), (101) and (102) reflections, indicating ordered staking of MWW layers. ${ }^{20}$ When the long chain quaternary ammonium surfactant was added into the gel, these samples such as $\mathrm{MZN}_{4}-12, \mathrm{MZN}_{4}-14$ and $\mathrm{MZN}_{4}-16$ also exhibited the peaks corresponding (101) and (102) reflections, but the bands assigned to the (101) and (102) peaks became broad, suggesting that the degree of long-rang order of MWW layer along the $c$ axis was decreased and the multilayered structure was formed. ${ }^{21}$ Besides, when the addition of MTAB was increased to the $8.0 \mathrm{wt} \%$, the intensity of (101) and (102) reflections for $\mathrm{MZN}_{8}-14$ was obviously decreased, and these reflections were transformed into a broad peak owing to disordered arrangement of MWW nanosheets along the $c$ direction and the mono-layer MWW zeolites may be produced. ${ }^{15}$ In addition, for all the multiple-layer and mono-layer samples, the (100) reflection can be observed, indicating that crystalline structure of MWW framework was maintained..$^{22}$ Moreover, the (002) reflection can be observed in the as-synthesized $\mathrm{MZN}_{4}-12$, $\mathrm{MZN}_{4}-14$ and $\mathrm{MZN}_{4}-16$ (Fig. S1) owing to the presence of interlayer structure. ${ }^{15}$ As the concentration of surfactant was increased to $8.0 \mathrm{wt} \%$ in synthesis gel, the (002) reflection of $\mathrm{MZN}_{8}-14$ dramatically decreased, indicating the loss of long-range order along the $c$-axis (Fig. S1).

To further investigate the delaminated degree of MWW zeolite nanosheets, the $\mathrm{N}_{2}$ adsorption/desorption experiments were carried out. It was observed from Fig. S2 that MCM-22 and $\mathrm{MZN}_{4}-12, \mathrm{MZN}_{4}-14$ and 
$\mathrm{MZN}_{4}-16$ presented a characteristic of micropore materials at $P / P_{0}<0.9$, while the sharp increase in the relative pressure ranges above 0.9 was attributed to the meso/macropores formed by MWW layers stacking. ${ }^{23}$ For $\mathrm{MZN}_{8}-14$, it exhibited a typical type-III isotherm with an obvious hydrolysis loop in the range of $P / P_{0}>$ 0.6 , indicating the presence of mesopores arised from intergrown and stacking of MWW nanosheets. ${ }^{21}$ Table S1 summarized the textural parameters of resultant MWW zeolites, it was noted that the micropore volume of MWW zeolite nanosheets was lower than MCM-22, which was reasonably attributed to the fact that the MWW zeolite nanosheets destroy the conventional stacking of MWW layer as like 3D order in MCM-22, resulting in the loss of 10-membered ring (MR) channels and 12-MR supercages along the caxis. ${ }^{15}$ However, the MWW zeolite nanosheets showed an enhanced fraction of mesoporous surface or volume compared with MCM-22 owing to the delaminated effect, which was expected to expose more accessible Brønsted acid sites. In addition, the concept of disorder index as ratio between the external and total surface areas was employed to identify the delaminated degree of MWW layers following Rimer et al's report, ${ }^{15}$ it was found that the degree of disorder for MWW zeolite nanosheets increased in the order of $\mathrm{MZN}_{4}-12<\mathrm{MZN}_{4}-14<\mathrm{MZN}_{4}-16$ $<\mathrm{MZN}_{8}-14$, indicating that the delaminated degree of MWW zeolite nanosheets can be tailored by tuning the length of long tail in surfactants due to distinct steric hindrance. Specially, when the amount of MTAB was increased to $8.0 \mathrm{wt} \%$, it greatly improved the separation of MWW layers since the sufficient surfactant can graft on every single MWW layer, which can inhibit the inductive effects between HMI with surface silanols, ${ }^{24}$ leading to the formation of mono-layer and presence of the highest disorder index.

The morphology of MCM-22 and MWW zeolite nanosheets was investigated by scanning electron microscope (SEM) images, as shown in Fig. 2 and Fig. S3. The MCM-22 showed bird's nest-like shape (Fig. 2a), this was typical morphology of non-agitated MCM-22 sample. ${ }^{25}$ While the $\mathrm{MZN}_{4}-12, \mathrm{MZN}_{4}-14$ and $\mathrm{MZN}_{4^{-}}$ 16 exhibited a thick plate-like morphology (Fig. S3). Particularly, $\mathrm{MZN}_{8}-14$ presented an interpenetrating network of nanosheets with ultrathin flake-like morphology (Fig. 2b), demonstrating that the additional surfactant can impede MWW layer alignment act as an exfoliating agent, and increasing the amount of surfactant was a more effective method to achieve the delaminated MWW zeolite with ultrathin nanosheets compared with tailoring the tail length of surfactants.

The delaminated nature of resultant MWW zeolite nanosheets was further investigated by transmission electron microscope (TEM) images, as depicted in Fig. 3 and Fig. S4. It was observed from Fig. S3 that the $\mathrm{MZN}_{4}-12, \mathrm{MZN}_{4}-14$ and $\mathrm{MZN}_{4}-16$ exhibited the discrete lamellar feature, but the thickness of these MWW layers was still thick, indicating that the additional surfactant can delaminate the 3D MWW zeolite to generate the lamellar structure on a certain degree. Specially, the $\mathrm{MZN}_{8}-14$ present an ultrathin nanosheets morphology (Fig. 3a-c) compared with conventional 3D MCM-22 with a thickness of $\sim 23 \mathrm{~nm}$ (Fig. 3ef), and the thickness of the MWW zeolite nanosheets was measured by atomic force microscope (AFM), which showed a uniform nanosheet thickness of $2.5 \pm 0.4 \mathrm{~nm}$ (Fig. 3d and Fig. S5), the average content of ultrathin nanosheets estimated from AFM images was about $73 \pm 5 \%$, suggesting that the mono-layer MWW nanosheets with single-unit-cell thickness was produced. ${ }^{22}$

Comparison of the catalytic properties of MWW zeolite nanosheets

The catalytic properties of MWW zeolite nanosheets were evaluated in the alkylation between benzene and 1-dodecene. It was noted from Fig. 4a that the MWW zeolite nanosheets exhibited a higher conversion than MCM-22 owing to the enhanced external Brønsted acid sites (Table S2 and Fig. S6), which originated from the delaminated process that can generate the MWW nanosheets and expose more accessible Brønsted acid sites. To verify the external Brønsted acid sites was main active sites for alkylation between benzene with 1-dodecene since it involves the bulk molecules, the pyridine and 2,6-di-tert-butylpyridine (DTBP) poisoning experiment of typical $\mathrm{MZN}_{4}-14$ were performed, as shown in Fig. S7. It was found that the pyridine poisoning $\mathrm{MZN}_{4}-14$ totally lost the activity, and the DTBP poisoning $\mathrm{MZN}_{4}-14$ maintained $8 \%$ conversion, the conversion dropped by $82 \%$ compared with fresh $\mathrm{MZN}_{4}-14$, indicating that the external Brønsted acid sites of MWW zeolites were main active sites in alkylation since they can be easily accessed compared with Brønsted acid sites located in the limited micropore channels. In addition, the conversion of MWW zeolite nanosheets increased in the order of $\mathrm{MZN}_{4}-12<\mathrm{MZN}_{4}-14<\mathrm{MZN}_{4}-16<\mathrm{MZN}_{8}-14$, which 
was in agreement with concentration of external Brønsted acid sites as shown in Table S2.

Moreover, the MWW zeolite nanosheets presented a comparable selectivity of 2-LAB (> $70 \%$ ) compared with MCM-22, as listed in Fig. 4b. As is known to everyone, the shape-selective catalysis for zeolites mainly depends on zeolite confined environments. Here, the alkylation mostly occurred on the external surface of MWW zeolites based on the aforementioned analysis, and MWW zeolite is a class of layer zeolite containing external isolated $12-\mathrm{MR}$ hemicavities with free internal diameter of $\sim 0.71 \mathrm{~nm}$, in which the alkylation takes place under exposed acid sites to produce the LAB. ${ }^{11}$ Therefore, the interaction between LAB isomers with 12-MR hemicavities was calculated by using Forcite module in Materials Studio in order to reveal why the MWW zeolite possessed comparable selectivity of 2-LAB regardless of MWW layers arrangement, as shown in Fig. 5. It was observed that 2-LAB had the highest binding energy and the best matched steric configuration with 12-MR cage located on MWW lamellar surface than other isomers, indicating that 2LAB can be steadily formed in the external confined 12-MR hemicavities of MWW zeolites, resulting in high selectivity of 2-LAB. With the reaction time increasing, the thermodynamic equilibrium mixture of $\mathrm{LAB}$ isomers was formed by reverse alkylation and isomerization steps ${ }^{26}$ leading to the selectivity of 2-LAB decreasing with reaction time increasing.

Fabrication of regularly spaced MWW zeolite nanosheets

Comprehensive analysis of the above data, it was found that tuning the tail length of long chain quaternary ammonium surfactant was not an appropriate strategy to effectively delaminate the MWW zeolites to produce the ultrathin MWW zeolite nanosheets. When excessive surfactant was used, it can produce the mono-layer MWW zeolites, but the nucleation of MWW zeolite was disrupted on a certain degree, resulting in low crystallinity (Fig. 1 and Table S1). For alkylation of benzene and 1-dodecene, the external Brønsted acid sites were main active sites. Thus, it's necessary to develop a strategy to fabricate the ultrathin MWW zeolite nanosheets without destroying their crystallinity in order to maximize the accessible Brønsted acid sites. The desired ultrathin MWW zeolite nanosheets not only have the single MWW unit cell thickness but also possess enough stability that can efficiently inhibit the layers stacking. Naturally, the pillaring ultrathin MWW zeolite nanosheets was an ideal approach to produce ordered MWW lamellas that can satisfy the above requirements.

The structure of regularly spaced MWW zeolite nanosheets was identified by PXRD technology, as presented in Fig. 6. It was noted that both of PMWW(31) and PMWW(74) exhibited the (001) reflections in the low-angle region of 1-5@, and the corresponding (002) and (003) can be found in PMWW(74), indicating that the resultant PMWW(74) possessed the characteristic of long-rang ordered structure even after multipillaring steps. ${ }^{16}$ For PMWW(31), the second-order reflection was missing due to mismatch between the thickness of a single MWW nanosheet and one-half of the adjacent-layer space, ${ }^{27}$ which demonstrated that the PMWW(31) maintained the long range order, but the degree of long range order was inferior compared with PMWW(74). By comparation, the MCM-22 didn't show any reflection in the low angle region of 1-5@ owing to its typical 3D structure. In addition, the (101) and (102) reflections were obviously visible in PMWW(74) and PMWW(31), which was different from the previous MCM-36 material that the (101) and (102) reflections were transformed into a broad peak due to the partial loss of the vertical alignment order of MWW layers along the $c$-axis. ${ }^{19}$ The presence of these reflections indicated that the ordered lamellar structure of MWW layers with the vertically aligned layers being ordered perpendicular to the $c$ axis in PMWW(74) and PMWW(31) was well maintained even after pillaring, ${ }^{28-30}$ which was also the typical characteristic of long-range order of MWW nanosheets in the $c$-direction. ${ }^{31}$ Therefore, the regularly spaced MWW zeolite nanosheets with long range order were fabricated based on the analysis of low-angle and high-angle PXRD data. Moreover, the only difference between PMWW(31) and PMWW(74) was discrepant $\mathrm{Si} / \mathrm{Al}$ ratios, $\mathrm{PMWW}(31)$ had the same $\mathrm{Si} / \mathrm{Al}$ ratio with aforesaid MWW zeolite nanaosheets in the synthesis of MCM-22(P) that was the precursor for fabrication of pillared MWW zeolites, and PMWW(74) increased the $\mathrm{Si} / \mathrm{Al}$ ratio.

For silica pillaring process, it can be performed through formation the Si-O-Si bonds between silanol groups from the MWW layers with silica pillar species, ${ }^{16}$ and the high Si/Al ratio of MWW layers can definitely 
influence the concentration of silanol groups located on the external surface of MWW layers. ${ }^{32}$ It's postulated that the MWW layers with high Si/Al ratio have sufficient opposing silanol groups in the neighboring layers, which is benefit to formation of ordered silica pillars. While the Si/Al ratio of MWW layers decreases, there is an increased probability of $\mathrm{Al}$ atoms becoming incorporated at external surface sites on the MWW layers, it reduces the concentration of terminal silanol groups in the adjacent layers, and further disrupts the pillaring process on a certain degree due to the slight deviations or mismatch between the position of silanol groups on each MWW layers, ${ }^{15}$ resulting in the low degree of long range order for PMWW(31), and the proposed influence of $\mathrm{Si} / \mathrm{Al}$ ratio on the pillaring process was illustrated in Scheme 1.

The pillared MWW zeolites were further investigated by $\mathrm{N}_{2}$ adsorption experiments, it was observed from Fig. S8a that PMWW(31) and PMWW(74) exhibited an increased adsorption at $P / P_{0}>0.4$, indicating the presence of mesoporosity caused by pillaring process, which was in accordance with previous report. ${ }^{16} \mathrm{By}$ comparison, MCM-22 achieved a saturation at a relative pressure of 0.1 owing to the sole micropores. The corresponding NLDFT (nonlocal density functional theory) pore size distribution of PMWW(31) and PMWW(74) (Fig. S8b) also presented a substantial increase in the range of $\left(1.2^{\sim} 3.3 \mathrm{~nm}\right)$ as a result of pillaring. Moreover, the textural data (Table S1) further corroborated that PMWW(31) and PMWW(74) had increased $S_{\text {ext }} S_{B E T}$ and $V_{\text {meso }} / V_{\text {tot }}$ owing to the effective pillaring procedure. In addition, the PMWW(31) and PMWW(74) showed a thin flake-like morphology with layers stacked in a lamellar arrangement (Fig. 7), and the framework structure of PMWW(31) and PMWW(74) were further investigated by TEM images, as shown in Fig. 8 and Fig. S9. It was noted from Fig. 8 that both PMWW(31) and PMWW(74) exhibited an ordered multilamellar architecture with a vertical distance of $\sim 1.8 \mathrm{~nm}$, the interlayer distance $(\sim 1.8 \mathrm{~nm})$ between the MWW nanosheets was almost equal to the theoretical length of MTAB surfactant $(\sim 1.75 \mathrm{~nm}){ }^{18}$ which was also in agreement with previous XRD data $(\sim 1.6 \mathrm{~nm})$, and the thickness of regularly spaced MWW nanosheets was $\sim 2.5 \mathrm{~nm}$ corresponding to one unit cell of MCM-22 in the $c$-axis. However, the multilamellar arrangement of PMWW(31) presented a litter deviation compared with PMWW(74) due to the low Si/Al ratio, which was in accordance with above analysis.

Initial optimization of the catalytic performance

Fig. 9 exhibited the catalytic performance of PMWW(31) and PMWW(74) in the liquid alkylation between benzene with 1-dodecene. As shown in Fig. 9a, PMWW(31) presented the comparable conversion of 1dodecene compared with $\mathrm{MZN}_{4}$-14 since they had the similar concentration of external Brønsted acid sites (Table S2). While PMWW(74) showed the best activity in all of investigated MWW zeolites due to its largest concentration of external Brønsted acid sites (Table S2, Fig. S10), and the fraction of external Brønsted acid sites for PMWW(74) achieved $88.5 \%$, indicating that the optimized pillaring process was an effective method to expose the accessible Brønsted acid sites. Moreover, the ${ }^{27} \mathrm{Al}$ multiquantum magic angle spinning (MQMAS) NMR spectroscopy was further conducted to reveal the potential differences in the spatial distribution of $\mathrm{Al}$ sites between PMWW(31) and PMWW(74) samples, as shown in Fig. 10.

The framework of MWW zeolite was composed of eight different T sites and three types of pores: 12-MR surface pockets, 10-MR windows accessing internal supercages and 10-MR sinusoidal channels, which was depicted in Fig. S11. It was noted from Fig. 10 that both PMWW(31) and PMWW(74) exhibited two peaks at around $\sim 56 \mathrm{ppm}$ and $0 \mathrm{ppm}$, which was assigned to the 4-coordinated framework $\left(\mathrm{Al}_{\mathrm{F}}\right)$ and 6 coordinated extra-framework aluminum $\left(\mathrm{Al} l_{\mathrm{EF}}\right)$ species, respectively. ${ }^{33}$ According to previous study, ${ }^{34}$ the broad peak around $\sim 56 \mathrm{ppm}$ can be resolved into three overlapped signals at 50, 56, and $61 \mathrm{ppm}$, which was attributed to $\mathrm{T}_{6}+\mathrm{T}_{7}(\delta=50 \mathrm{ppm}), \mathrm{T}_{1}+\mathrm{T}_{3}+\mathrm{T}_{4}+\mathrm{T}_{5}+\mathrm{T}_{8}(\delta=56 \mathrm{ppm})$ and $\mathrm{T}_{2}(\delta=61$ $\mathrm{ppm})$, respectively. Following this way, the broad peak around $\sim 56 \mathrm{ppm}$ was deconvoluted, as presented in Table S3 and Fig. 10. It was observed that the proportion of $\mathrm{Al}_{\mathrm{F}(50)}$ species for $\mathrm{PMWW}(31)$ was about $49 \%$ (the combination of $\delta=50$ and $\delta=51$ ), indicating the $\mathrm{Al}_{\mathrm{F}}$ species mainly located in the supercages and surface pockets, ${ }^{35}$ in which the alkylation occurred as a result of accessible Brønsted acid sites arised from the $\mathrm{Al}_{\mathrm{F}(50)}$ species. While the $\mathrm{Al}_{\mathrm{F}(61)}$ species for PMWW(31) was missing, which demonstrated that proportion of $\mathrm{Al}_{\mathrm{F}(61)}$ species in $\mathrm{PMWW(31)}$ was negligible. However, $\mathrm{Al}_{\mathrm{F}(61)}$ species were related to $\mathrm{T}_{2}$ sites that located on the exterior surface of MWW nanosheets close to the outer edge of the 12-MR pockets, 
and the $\mathrm{T}_{2}$ sites was the most accessible to bulky adsorbates. ${ }^{15}$ In this point of view, it was reasonable that PMWW(74) had an advantage over PMWW(31) in the alkylation due to the presence of considerable $\mathrm{Al}_{\mathrm{F}(61)}$ species ( $13 \%$ ). In addition, $\mathrm{PMWW}(31)$ and $\mathrm{PMWW}(74)$ possessed the similar quantity of $\mathrm{Al}_{\mathrm{EF}(0)}$ species. Fig. 9b showed that PMWW(31) and PMWW(74) had comparable selectivity of 2-LAB regardless of the multilamellar arrangement of MWW zeolite nanosheets, because PMWW(31) and PMWW(74) shared the same 12-MR hemicavities structure on the upper and lower surface of MWW layers, ${ }^{36}$ which was in line with above computer calculation data (Fig. 5). These analyses corroborated that the fabrication of order multilamellar arrangement of MWW nanosheets and precise control of Al species distribution can greatly expose the accessible Brønsted acid sites.

Stability, acidity and catalytic performance of regularly spaced MWW zeolite nanosheets

The stability, acidity and catalytic performance of optimized PMWW(74) was further investigated in the alkylation between benzene with 1-dodecene. As shown in Fig. 11a, the conversion of 1-dodecene for PMWW(74) and MCM-22 was $85 \%$ and $40 \%$ in the first cycle, respectively. With the number of cycles increasing, the activity of PMWW(74) and MCM-22 all displayed the tendency declining. For MCM-22, the conversion dropped to $19 \%$ after five cycles, while PMWW(74) still maintained $68 \%$ conversion even after five recycling experiments, indicating that PMWW(74) possessed strong stability compared with MCM-22 due to the enhanced diffusion of PMWW(74) with open single-layered structure. ${ }^{21}$ As shown in Fig. S12 and Table S4, which clearly verified that the effective diffusional time constants ( $D$ eff $\left./ r^{2}\right)$ of PMWW(74) was higher than MCM-22. Interestingly, the selectivity of 2-LAB for MWW zeolite catalysts was almost not influenced after cycle experiments (Fig. 11b), because MWW zeolite possessed special 12-MR pockets on the exterior surfaces that had the best matched steric configuration and charge force with 2-LAB isomer.

To examine the structure of zeolite catalysts before and after cycles, the corresponding XRD, $\mathrm{N}_{2}$ adsorptiondesorption isotherm and acidity of fresh and spent catalysts after five cycles were performed, as given in Fig. 12, Fig. S13 and Fig. S14, respectively. It was observed from Fig. 12 that both PMWW(74) and MCM-22 exhibited the robust stability with similar reflection patterns before and after cycles. However, the coalescence of the (101) and (102) diffraction peaks into a broadband reflection for spent PMWW(74) was observed, indicating partial loss of vertical alignment order in the stacking $c$ direction in the recycle experiments ${ }^{37}$ but (001) and (002) reflections were still preserved, suggesting that multilamellar structure of PMWW(74) was also totally preserved. ${ }^{16}$ In addition, the fresh PMWW(74) and spent PMWW(74) showed the comparable $\mathrm{N}_{2}$ adsorption-desorption isotherms (Fig. S13) and textural parameters (Table S1), suggesting that multilamellar arrangement of MWW nanosheets over PMWW(74) was not destroyed, but the spent MCM-22 exhibited a decreased BET surface area $\left(557 \mathrm{~m}^{2} \mathrm{~g}^{-1}\right.$ to $451 \mathrm{~m}^{2} \mathrm{~g}^{-1}$, Table S1), indicating that the channels of MCM-22 was blocked on a certain degree due to diffusion limitation under the sole micropores. Moreover, the total Brønsted acid sites and external Brønsted acid sites of PMWW(74) and MCM-22 after five cycles were examined, as presented in Fig. S14 and Table S2. It was observed from Table S2 that the total Brønsted acid sites and external Brønsted acid sites of spent MCM-22 dropped by $83.2 \%$ and $34.6 \%$, respectively. While the total Brønsted acid sites and external Brønsted acid sites of spent PMWW(74) decreased by $32.3 \%$ and $30.6 \%$, respectively. These data confirmed that multilamellar arrangement of MWW nanosheets for PMWW(74) exhibited the evident advantage of architecture compared with conventional 3D MCM-22, in which the sole micropores of MCM-22 suffered from serious diffusion limitation during the alkylation and their narrow micropore entrance was easily blocked by bulk alkylbenzene products ${ }^{21}$ resulting in the concentration of total Brønsted acid sites drastically decreasing after cycles.

\section{Conclusions}

In summary, multiple-layer and mono-layer MWW zeolite nanosheets were fabricated through the dual template synthesis strategy with conventional HMI and long chain surfactants, in terms of multi-layered MWW thickness or single-unit-cell thickness along the $c$-axis with a large number of exposed Brønsted acid sites. This strategy works well on a layered MWW zeolite system that simultaneously integrates exposed Brønsted acid sites and shape-selectivity, which exhibits excellent catalytic activity and selectivity towards 2$\mathrm{LAB}$ in the alkylation between benzene with 1-dodecene. Mechanistic insights are provided that the superior 
catalytic performance originates from the raised accessible Brønsted acid sites, enhanced molecular diffusion and solid interactions between adsorbate and 12-MR pockets on the exterior surface. From our investigation, it's clear that in order to achieve higher 1-dodecene conversion with MWW zeolite nanosheets system, a modification of the MWW nanosheets to allow i) delamination of layered MWW zeolites into the single-unitcell nanosheet, ii) assembling the single-unit-cell nanosheets into ordered multilamellar arrangement and iii) precise control of $\mathrm{Al}$ species distribution in discrepant $\mathrm{T}$ sites must be found. Therefore, our present work lays the foundation for catalysts design in the future to fulfill this task, but our study already produces regularly spaced MWW zeolite nanosheets with harmonic Al distribution, representing an important finding.

\section{Associated content}

\section{Supporting Information}

Experimental contents for synthesis and characterization of MWW zeolites; the study of catalytic and diffusion performance of MWW zeolites; additional XRD, AFM, SEM, ${ }^{27} \mathrm{Al}$ MAS NMR, FTIR, TEM, $\mathrm{N}_{2}$ isotherm data and Acidity analysis.

\section{Acknowledgment}

This work was supported by National Natural Science Foundation of China (No. 21978055 and 21808040), and "High-level Talents Program" of Pearl River (2017GC010080).

\section{References}

1. de Almeida JLG, Dufaux M, Taarit YB, Naccache C. Linear alkylbenzene. J. Am. Oil. Chem. Soc. 1994;71(7):675-694.

2. Yadav GD, Doshi NS. Synthesis of Linear Phenyldodecanes by the Alkylation of Benzene with 1-Dodecene over Non-Zeolitic Catalysts. Org. Process Res. Dev.2002;6(3):263-272.

3. Cao Y, Kessas R, Naccache C, Ben Taarit Y. Alkylation of benzene with dodecene. The activity and selectivity of zeolite type catalysts as a function of the porous structure. Appl. Catal., A. 1999;184(2):231238.

4. Tsai T-C, Wang I, Li S-J, Liu J-Y. Development of a green LAB process: alkylation of benzene with 1-dodecene over mordenite. Green Chem. 2003;5(4):404-409.

5. Sivasanker S, Thangaraj A. Distribution of isomers in the alkylation of benzene with long-chain olefins over solid acid catalysts. J. Catal. 1992;138(1):386-390.

6. Kocal JA, Vora BV, Imai T. Production of linear alkylbenzenes. Appl. Catal., A.2001;221(1):295-301.

7. Aitani A, Wang JB, Wang I, Al-Khattaf S, Tsai T-C. Environmental Benign Catalysis for Linear Alkylbenzene Synthesis: A Review. Catal. Surv. from Asia.2014;18(1):1-12.

8. Harmer MA, Sun Q. Solid acid catalysis using ion-exchange resins. Appl. Catal., A.2001;221(1):45-62.

9. Mokaya R, Jones W. Pillared Clays and Pillared Acid-Activated Clays: A Comparative-Study of Physical, Acidic, and Catalytic Properties. J. Catal.1995;153(1):76-85.

10. Zhang J, Zhu Z, Li C, Wen L, Min E. Characterization and kinetic investigation of tungstophosphoric supported on $\mathrm{SiO} 2$ for alkylation of benzene with 1-dodecene to synthesize linear alkylbenzene. J. Mol. Catal. A: Chem. 2003;198(1):359-367.

11. Wang J-J, Chuang Y-Y, Hsu H-Y, Tsai T-C. Toward industrial catalysis of zeolite for linear alkylbenzene synthesis: A mini review. Catal. Today.2017;298:109-116.

12. Jian LIU HL, Bin TAN, Ping LI, Jianhong XU. Research progress in long chain catalytic alkylation of aromatic hydrocarbons. Chem. Ind. Eng. Prog.2020;39(5):1744-1755. 
13. Zheng YW, Yi MW. Catalytic Application of Mesoporous ZSM-5 Zeolite. Curr. Org. Chem. 2014;18(10):1305-1322.

14. Sugi Y, Vinu A. Alkylation of Biphenyl over Zeolites: Shape-Selective Catalysis in Zeolite Channels. Catal. Surv. from Asia. 2015;19(3):188-200.

15. Zhou Y, Mu Y, Hsieh M-F, et al. Enhanced Surface Activity of MWW Zeolite Nanosheets Prepared via a One-Step Synthesis. J. Am. Chem. Soc. 2020;142(18):8211-8222.

16. Maheshwari S, Jordan E, Kumar S, et al. Layer Structure Preservation during Swelling, Pillaring, and Exfoliation of a Zeolite Precursor. J. Am. Chem. Soc.2008;130(4):1507-1516.

17. Lv D, Wu Y, Chen J, et al. Improving CH4/N2 selectivity within isomeric Al-based MOFs for the highly selective capture of coal-mine methane. AIChE J.2020;66(9):e16287.

18. Zhang Y, Kubů M, Mazur M, Čejka J. Synthesis of Pt-MWW with controllable nanoparticle size.Catal Today. 2019;324:135-143.

19. Roth WJ, Nachtigall P, Morris RE, Čejka J. Two-Dimensional Zeolites: Current Status and Perspectives. Chem. Rev. 2014;114(9):4807-4837.

20. Leonowicz ME, Lawton JA, Lawton SL, Rubin MK. MCM-22: A Molecular Sieve with Two Independent Multidimensional Channel Systems. Science.1994;264(5167):1910-1913.

21. Chen J-Q, Li Y-Z, Hao Q-Q, et al. Controlled direct synthesis of single- to multiple-layer MWW zeolite. Natl. Sci. Rev. 2020;236:1-8.

22. Sabnis S, Tanna VA, Li C, et al. Exfoliation of two-dimensional zeolites in liquid polybutadienes. Chem.Commun. 2017;53(52):7011-7014.

23. Wang Z, Cichocka MO, Luo Y, et al. Controllable direct-syntheses of delaminated MWW-type zeolites. Chinese J. Catal. 2020;41(7):1062-1066.

24. Položij M, Thang HV, Rubeš M, Eliášová P, Čejka J, Nachtigall P. Theoretical investigation of layered zeolites with MWW topology: MCM-22P vs. MCM-56. Dalton Trans. 2014;43(27):10443-10450.

25. Carriço CS, Cruz FT, Santos MB, Pastore HO, Andrade HMC, Mascarenhas AJS. Efficiency of zeolite MCM-22 with different SiO2/Al2O3 molar ratios in gas phase glycerol dehydration to acrolein. Microporous Mesoporous Mater.2013;181:74-82.

26. Olson A. Alkylation of Aromatics with 1-Alkenes. Ind. Eng. Chem. 1960;52(10):833-836.

27. Na K, Choi M, Park W, Sakamoto Y, Terasaki O, Ryoo R. Pillared MFI Zeolite Nanosheets of a SingleUnit-Cell Thickness. J. Am. Chem. Soc.2010;132(12):4169-4177.

28. He YJ, Nivarthy GS, Eder F, Seshan K, Lercher JA. Synthesis, characterization and catalytic activity of the pillared molecular sieve MCM-36. Microporous Mesoporous Mater. 1998;25(1):207-224.

29. Jankowska A, Kowalczyk A, Rutkowska M, Mozgawa W, Gil B, Chmielarz L. Silica and silica-titania intercalated MCM-36 modified with iron as catalysts for selective reduction of nitrogen oxides - the role of associated reactions. Catal. Sci. Technol. 2020;10(23):7940-7954.

30. Marosz M, Samojeden B, Kowalczyk A, et al. MCM-22, MCM-36, and ITQ-2 Zeolites with Different Si/Al Molar Ratios as Effective Catalysts of Methanol and Ethanol Dehydration. Mater. 2020;13(10):2399.

31. Hao Q-Q, Lei C-Y, Song Y-H, Liu Z-T, Liu Z-W. The delaminating and pillaring of MCM-22 for Fischer-Tropsch synthesis over cobalt. Catal Today.2016;274:109-115.

32. Corma A, Díaz U, García T, Sastre G, Velty A. Multifunctional Hybrid Organic-Inorganic Catalytic Materials with a Hierarchical System of Well-Defined Micro- and Mesopores. J. Am. Chem. Soc. 2010;132(42):15011-15021. 
33. Corma A, Corell C, Fornes V, Kolodziejski W, Perez-Pariente J. Infrared spectroscopy, thermoprogrammed desorption, and nuclear magnetic resonance study of the acidity, structure, and stability of zeolite MCM-22. Zeolites.1995;15(7):576-582.

34. Kennedy GJ, Lawton SL, Fung AS, Rubin MK, Steuernagel S. Multinuclear MAS NMR studies of zeolites MCM-22 and MCM-49. Catal Today. 1999;49(4):385-399.

35. Chen J, Liang T, Li J, et al. Regulation of Framework Aluminum Siting and Acid Distribution in HMCM-22 by Boron Incorporation and Its Effect on the Catalytic Performance in Methanol to Hydrocarbons. ACS Catal.2016;6(4):2299-2313.

36. Schwanke A, Pergher S. Lamellar MWW-Type Zeolites: Toward Elegant Nanoporous Materials.Appl. Sci. 2018;8(9):1636.

37. Schwanke AJ, Pergher S, Diaz U, Corma A. The influence of swelling agents molecular dimensions on lamellar morphology of MWW-type zeolites active for fructose conversion. Microporous Mesoporous Mater. 2017;254:17-27.

\section{Figure Captions}

Figure. 1 XRD patterns of various calcined MWW zeolite samples.

Figure. 2 SEM images of (a) MCM-22 and (b) $\mathrm{MZN}_{8}-14$.

Figure. 3 (a-c) TEM images of $\mathrm{MZN}_{8}-14$ with different magnitude, (d) AFM topographic image of $\mathrm{MZN}_{8^{-}}$ 14 on a mica disc (inset, the profile analysis of the topographic height along the line scan of the MWW nanosheet shown in (d)), (e-f) TEM images of MCM-22 with different magnitude.

Figure. 4 (a) Conversion of 1-dodecene and (b) selectivity of 2-LAB with reaction time over various MWW zeolites.

Figure. 5 The binding energy of LAB isomers with 12- membered ring pockets on the exterior surface of MWW layer and the corresponding adsorption configuration.

Figure. 6 XRD patterns of calcined PMWW(31), PMWW(74) and MCM-22 samples.

Figure. 7 SEM images of (a) PMWW(31) and (b) PMWW(74).

Figure. 8 TEM images of (a) PMWW(31) and (b) PMWW(74).

Figure. 9 (a) Conversion of 1-dodecene and (b) selectivity of 2-LAB with reaction time over PMWW(31) and $\mathrm{PMWW}(74)$, respectively.

Figure. $10 \mathrm{Al}^{27}$ MAS NMR spectra of (a) PMWW(31) and (b) PMWW(74) with the deconvolution and curve fitting.

Figure. 11 (a) Conversion of 1-dodecene and (b) selectivity of 2-LAB over MCM-22 and PMWW(74) with different cycles.

Figure. 12 XRD patterns of MCM-22 and PMWW(74) before and after 5 cycles.

Scheme 1 The proposed arrangements of pillared MWW lamellar at (a) high and (b) low Si/Al ratios. 


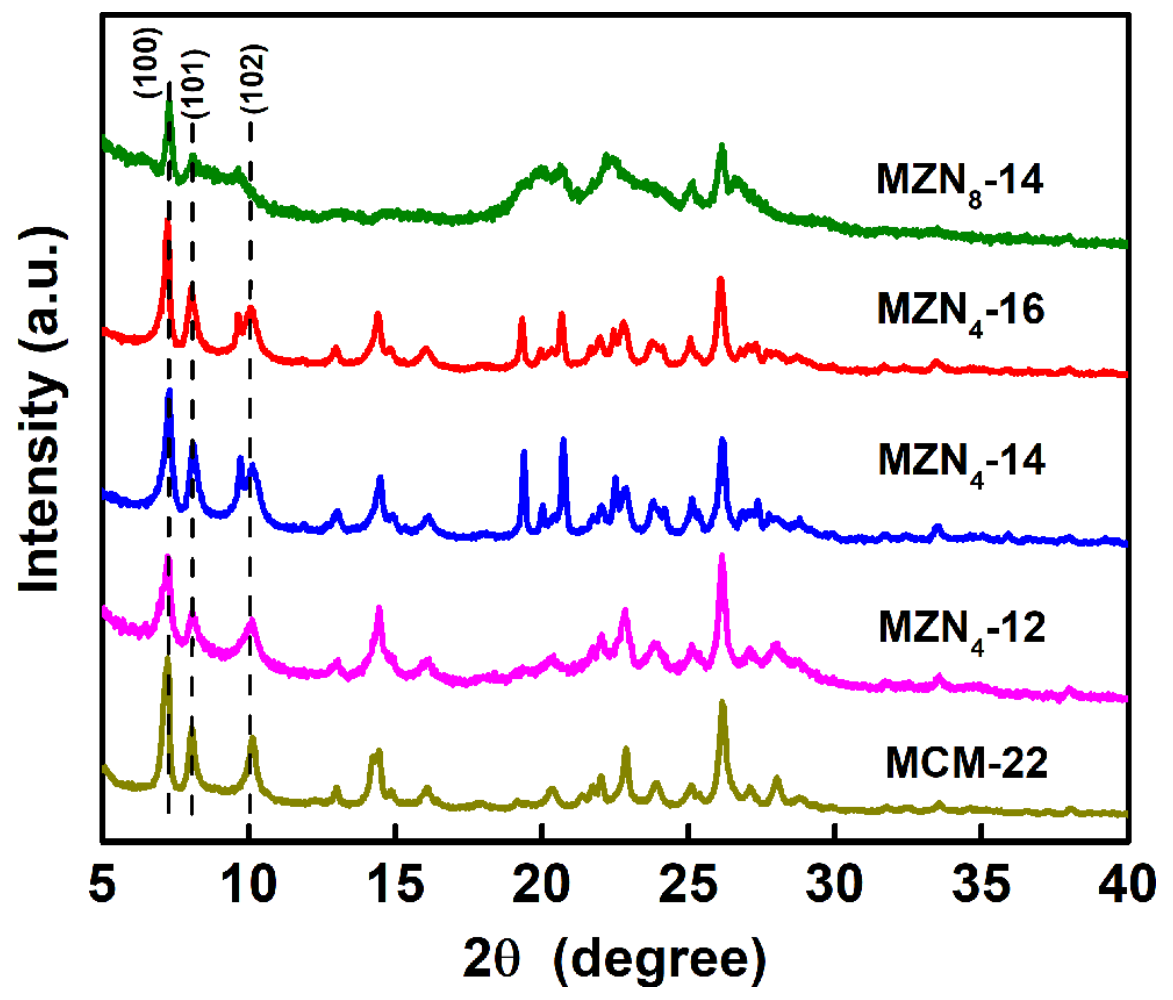

Figure. 1 XRD patterns of various calcined MWW zeolite samples.
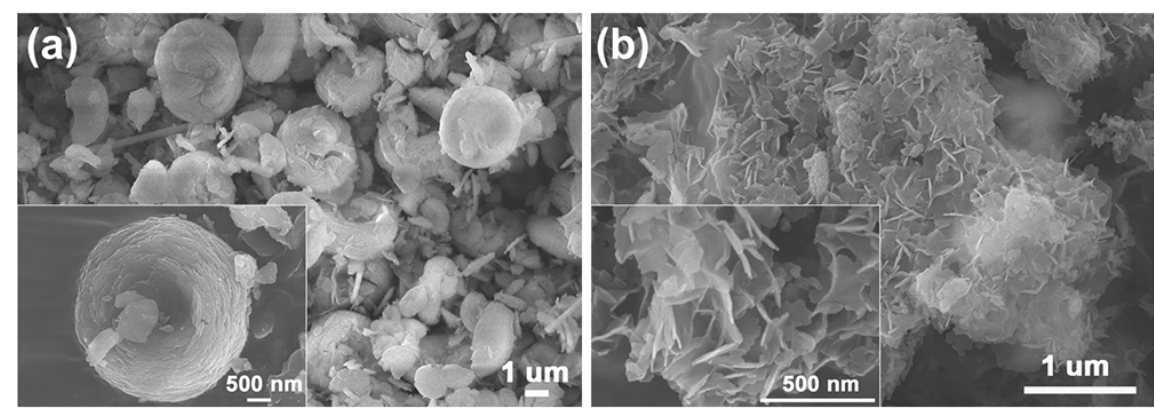

Figure. 2 SEM images of (a) MCM-22 and (b) $\mathrm{MZN}_{8}-14$. 

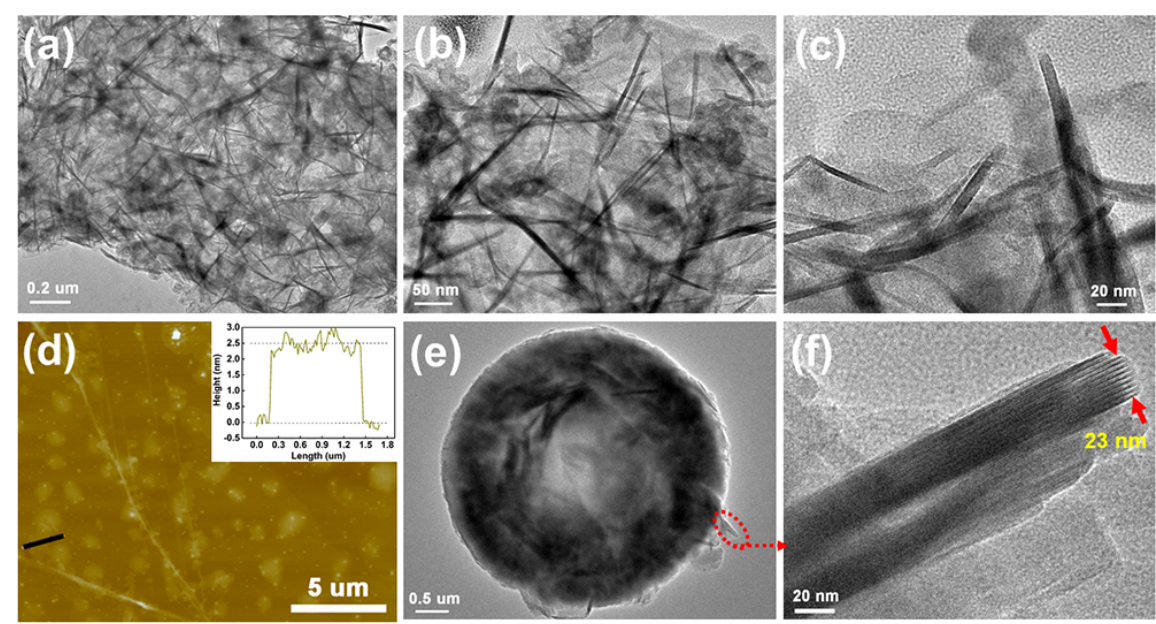

Figure. 3 (a-c) TEM images of $\mathrm{MZN}_{8}-14$ with different magnitude, (d) AFM topographic image of $\mathrm{MZN}_{8^{-}}$ 14 on a mica disc (inset, the profile analysis of the topographic height along the line scan of the MWW nanosheet shown in (d)), (e-f) TEM images of MCM-22 with different magnitude.

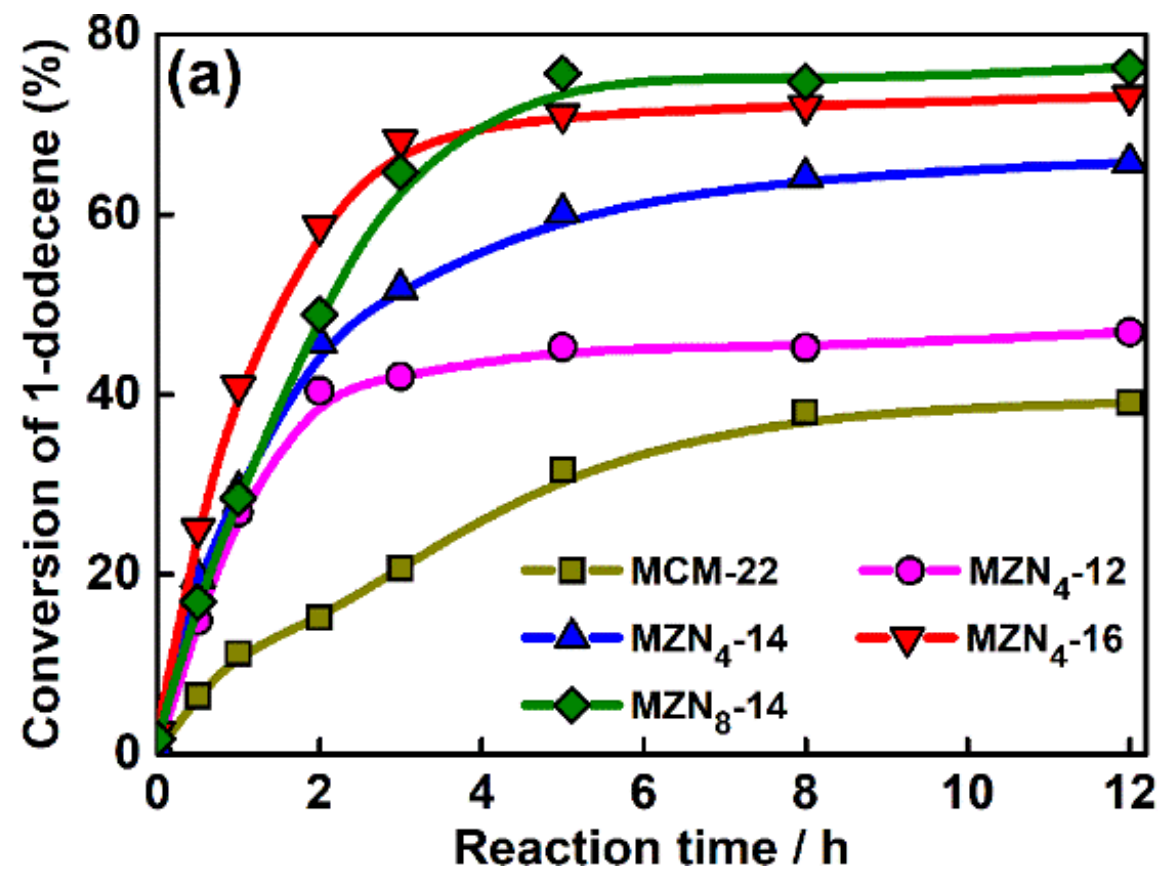




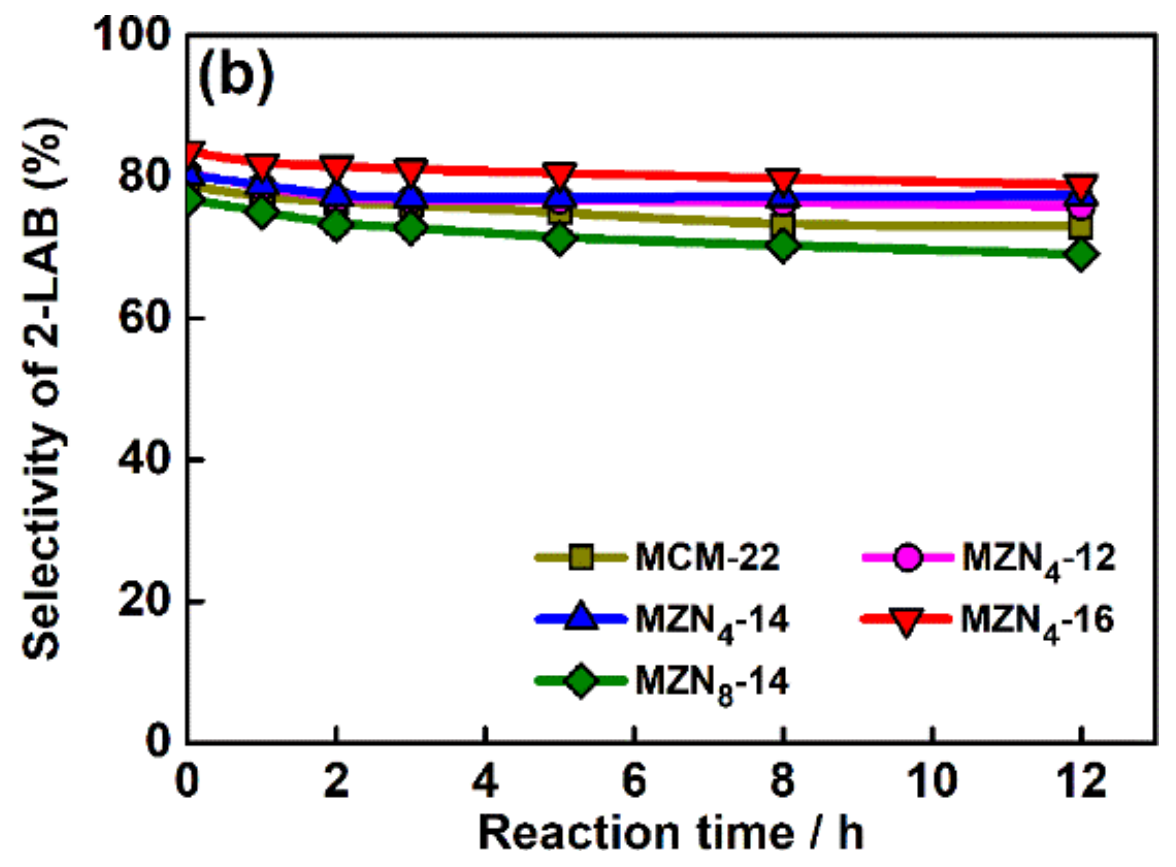

Figure. 4 (a) Conversion of 1-dodecene and (b) selectivity of 2-LAB with reaction time over various MWW zeolites.
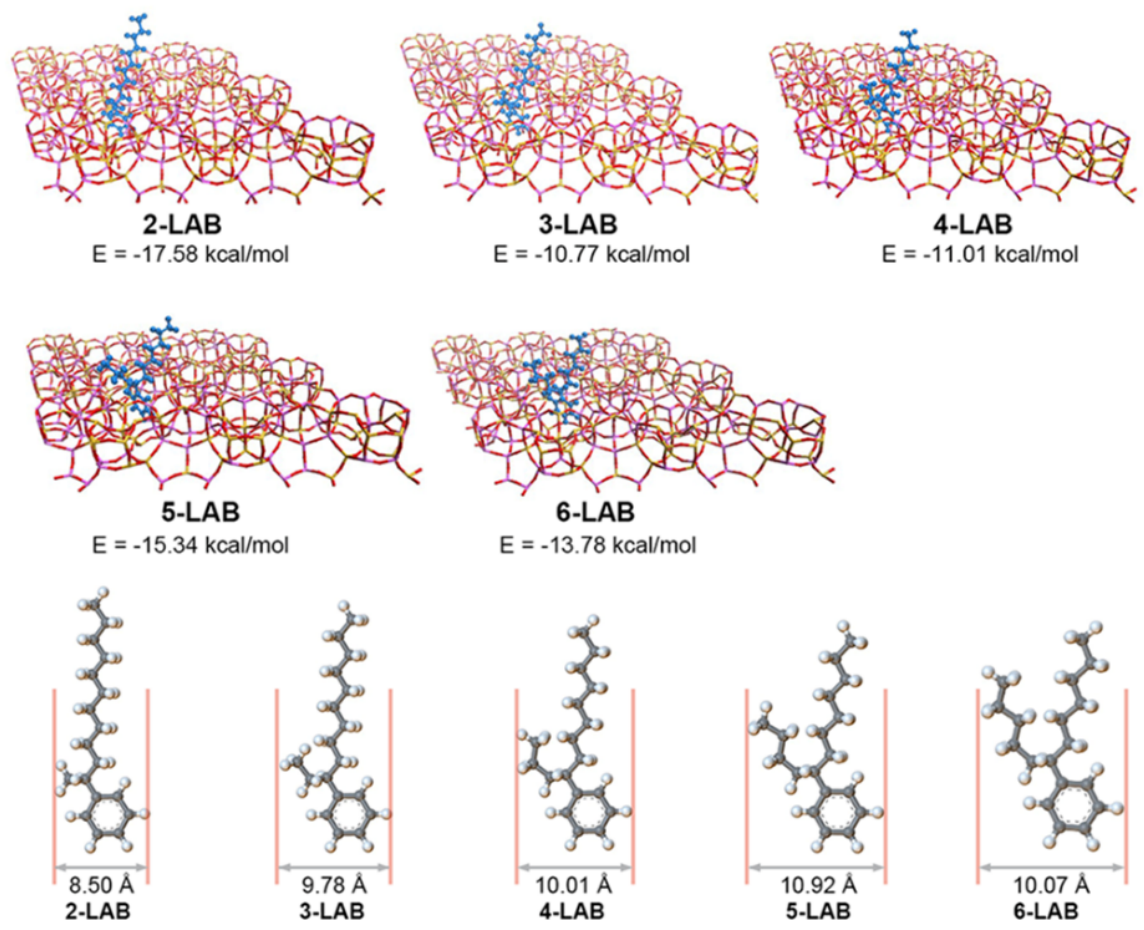

Figure. 5 The binding energy of LAB isomers with 12- membered ring pockets on the exterior surface of MWW layer and the corresponding adsorption configuration. 


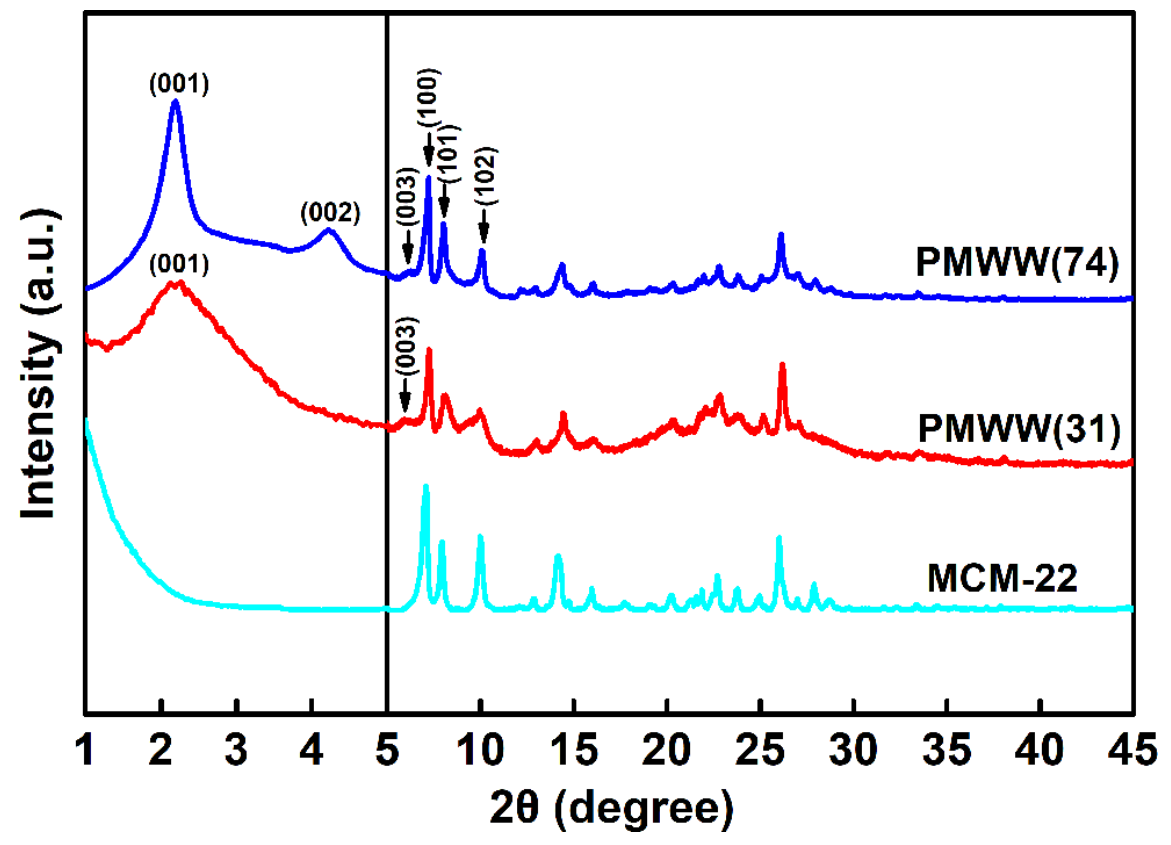

Figure. 6 XRD patterns of calcined PMWW(31), PMWW(74) and MCM-22 samples.
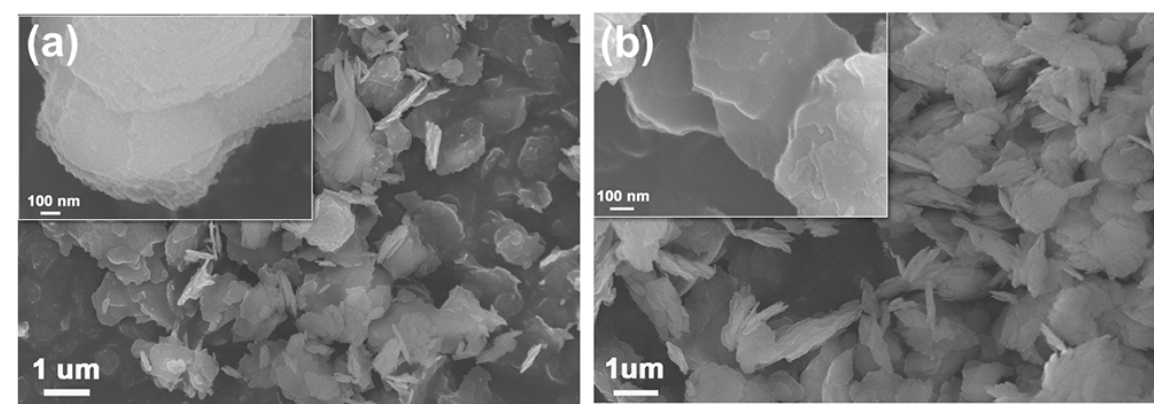

Figure. 7 SEM images of (a) PMWW(31) and (b) PMWW(74). 


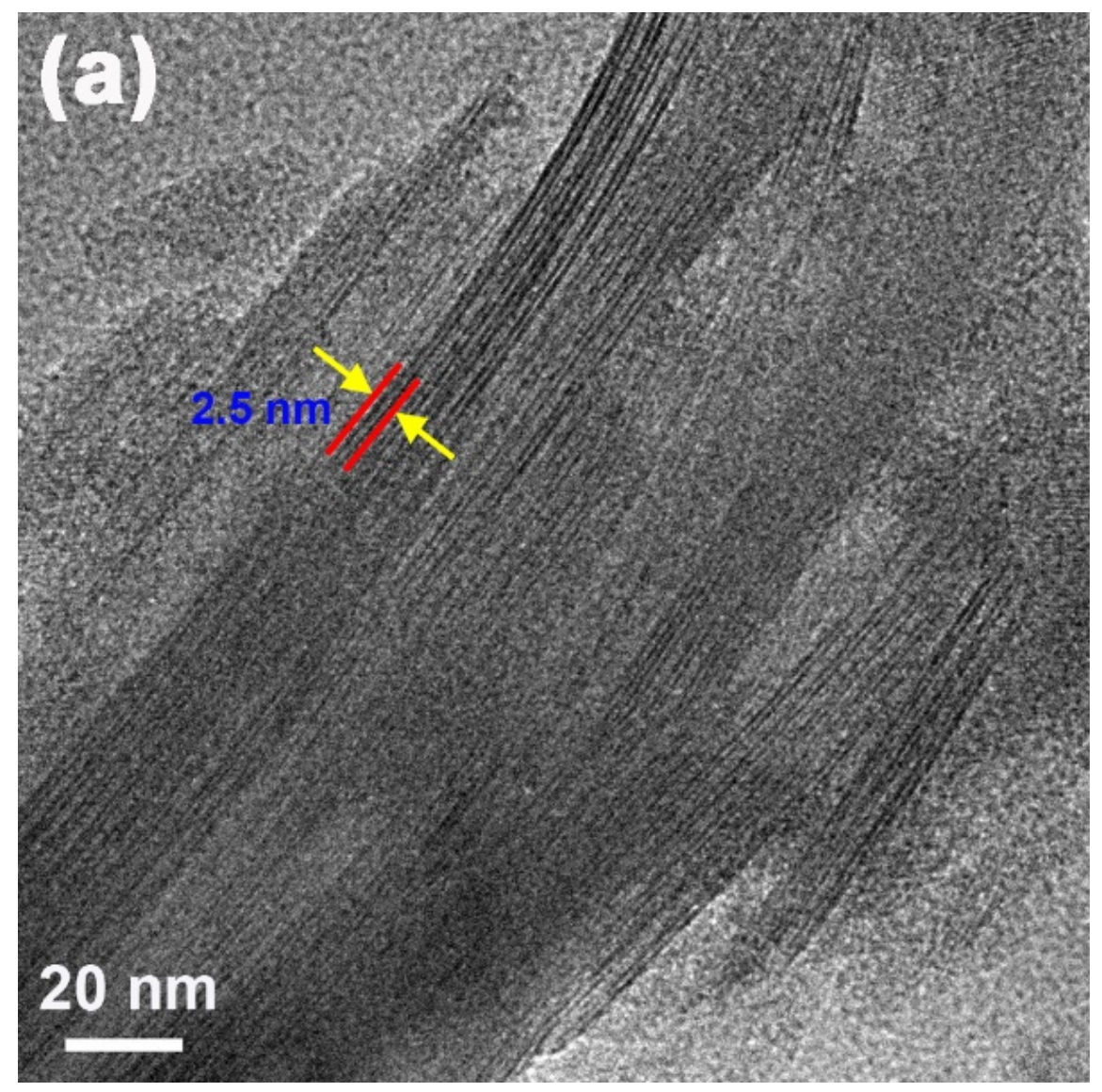




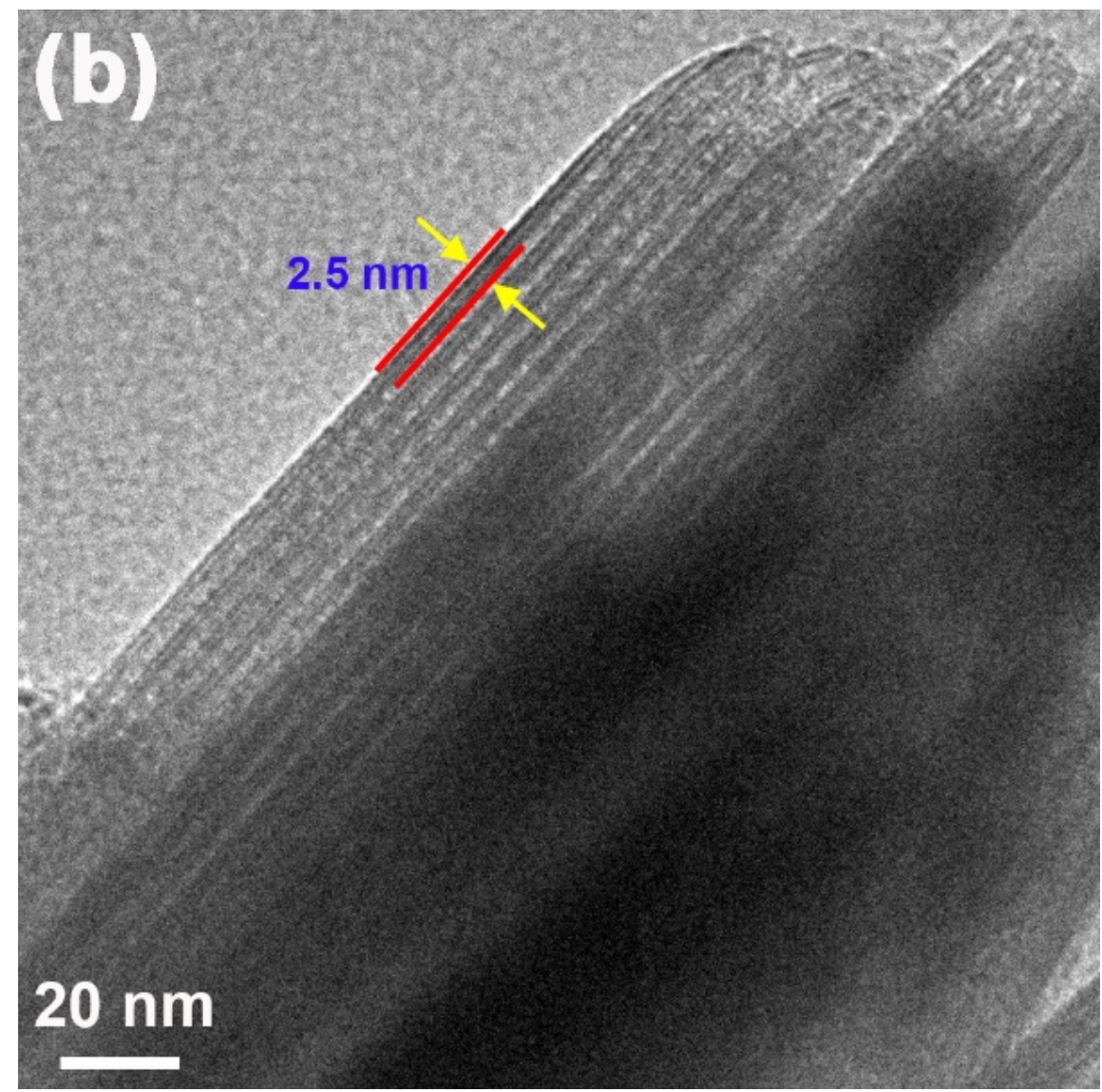

Figure. 8 TEM images of (a) PMWW(31) and (b) PMWW(74).

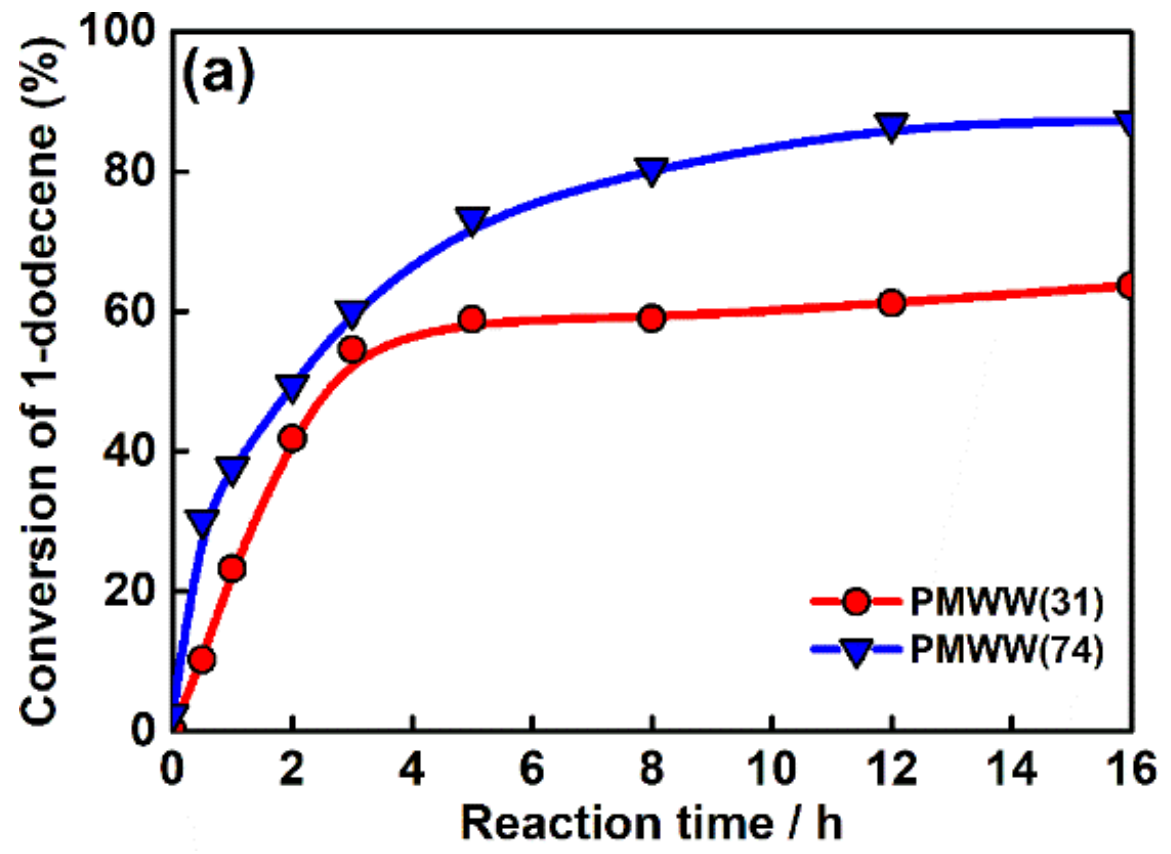




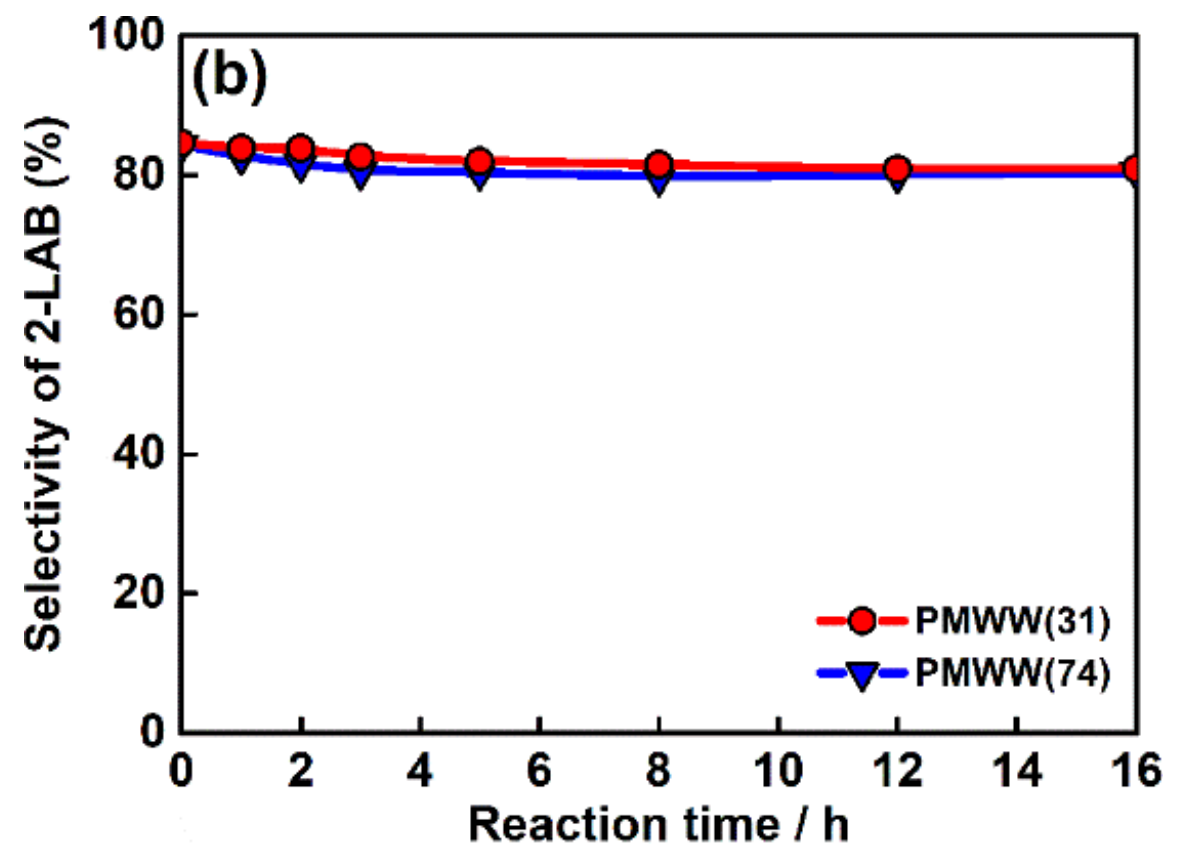

Figure. 9 (a) Conversion of 1-dodecene and (b) selectivity of 2-LAB with reaction time over PMWW(31) and PMWW(74), respectively.

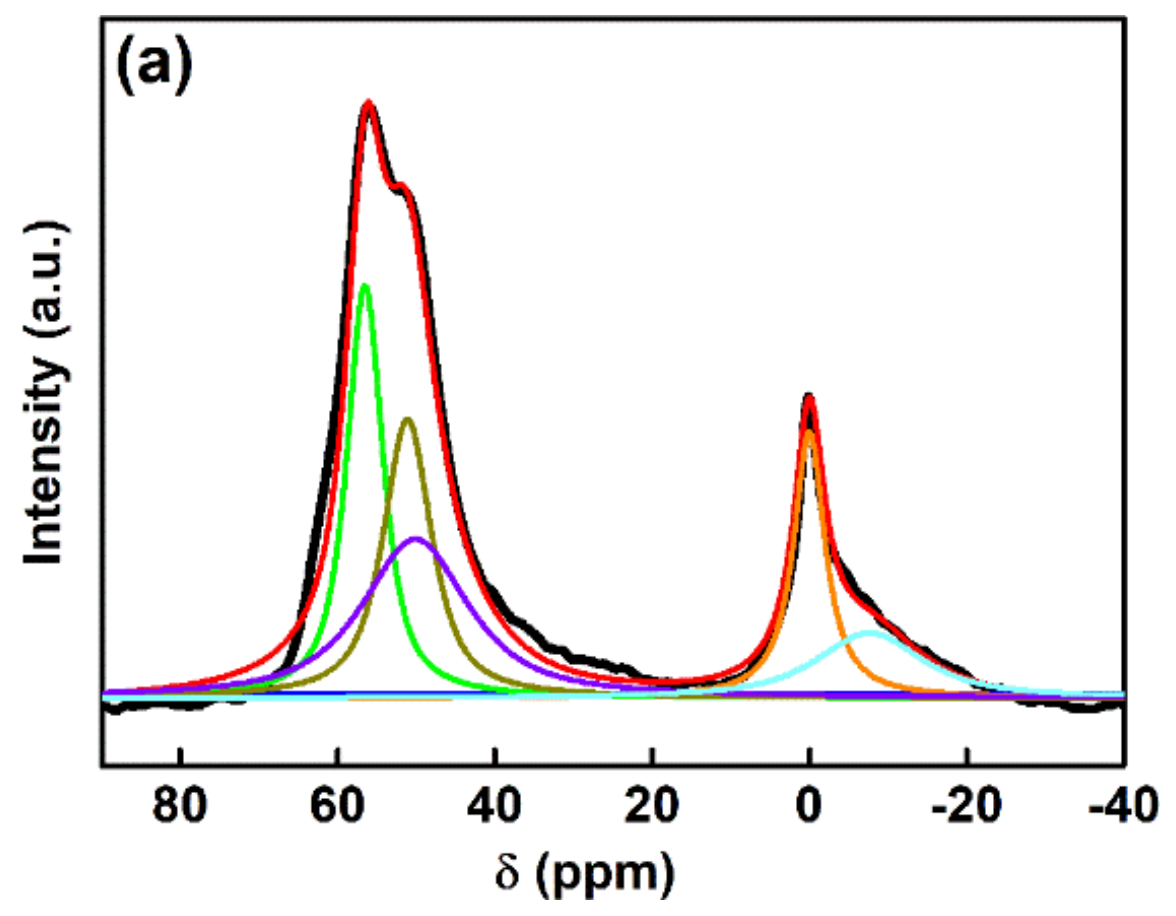




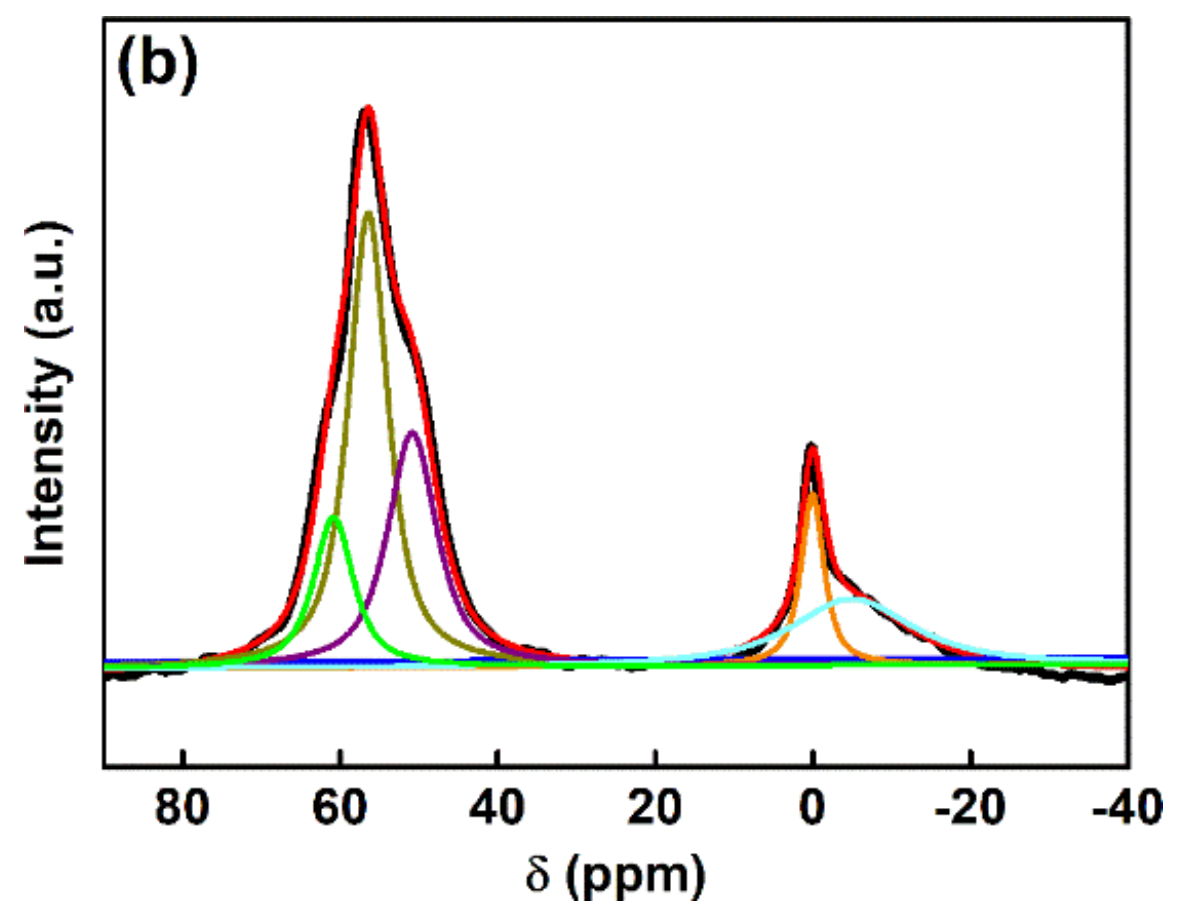

Figure. $10 \mathrm{Al}^{27}$ MAS NMR spectra of (a) PMWW(31) and (b) PMWW(74) with the deconvolution and curve fitting.

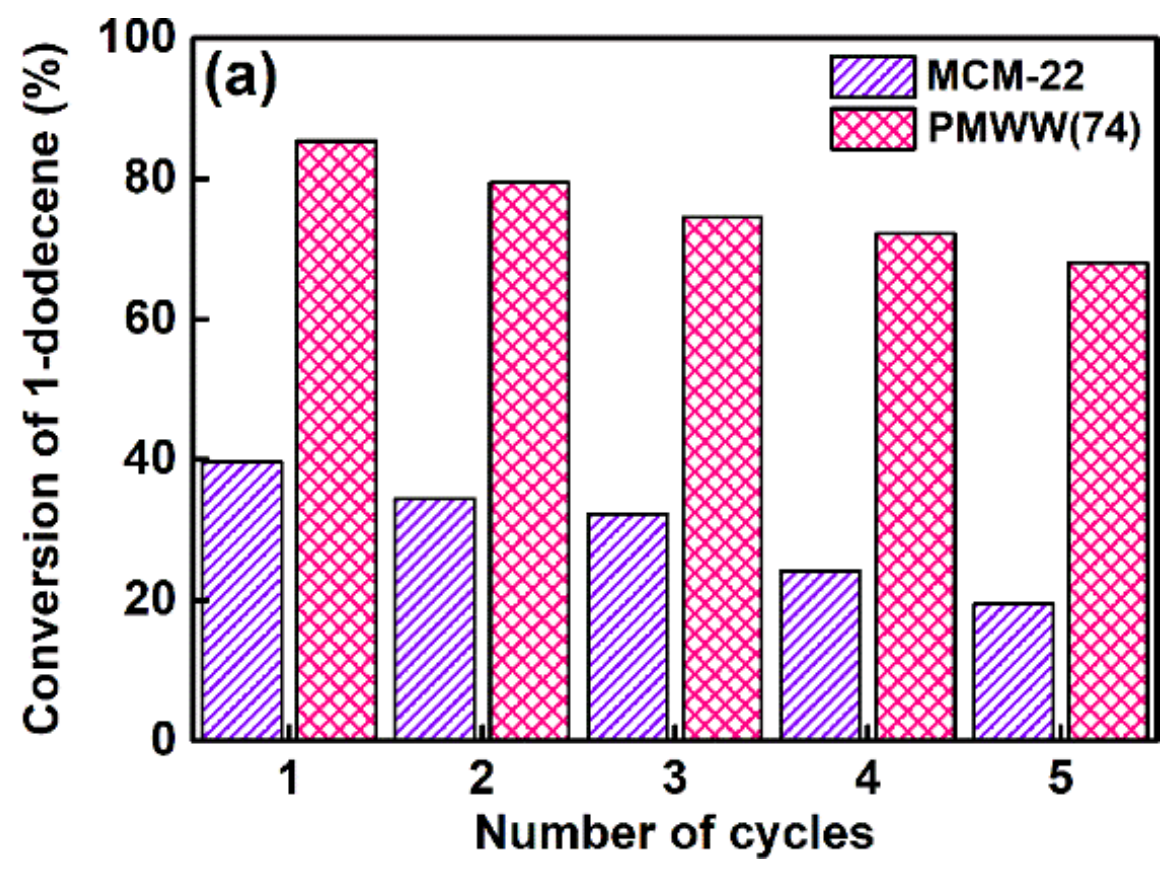




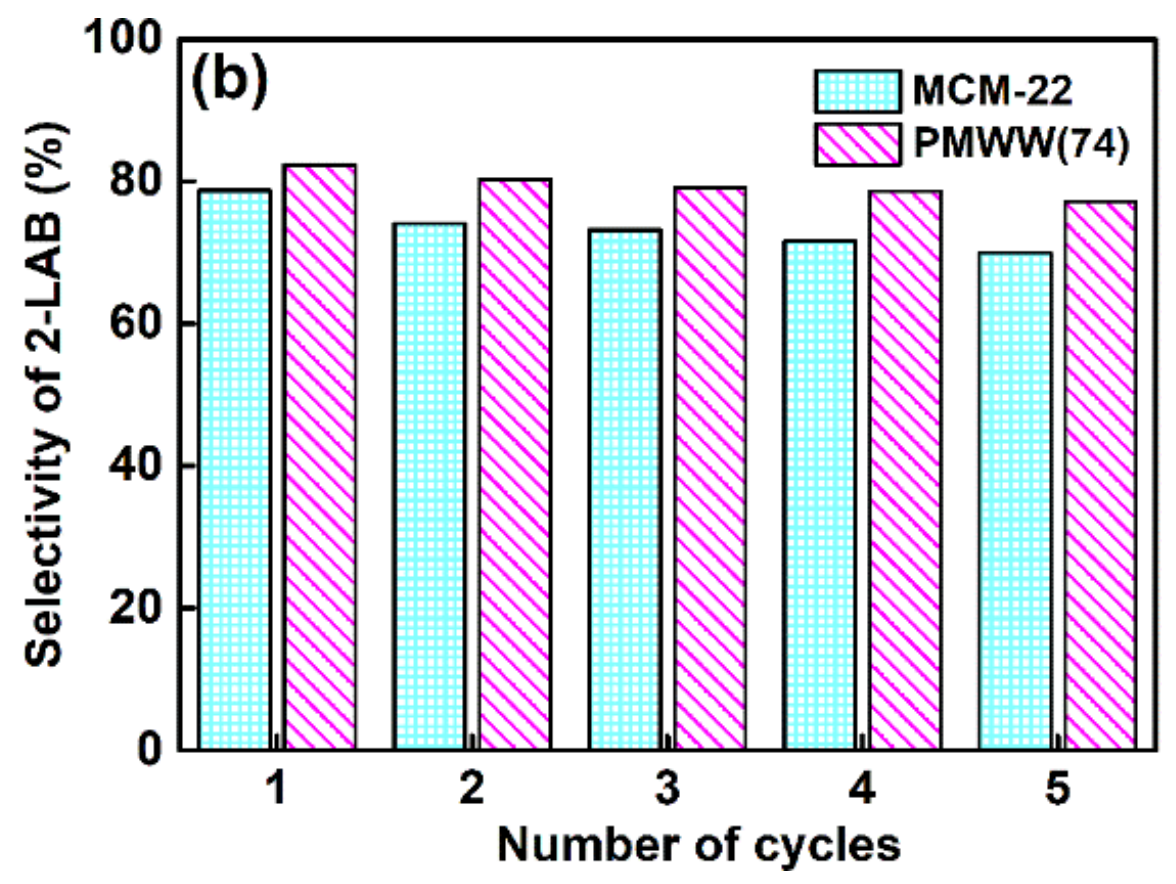

Figure. 11 (a) Conversion of 1-dodecene and (b) selectivity of 2-LAB over MCM-22 and PMWW(74) with different cycles.

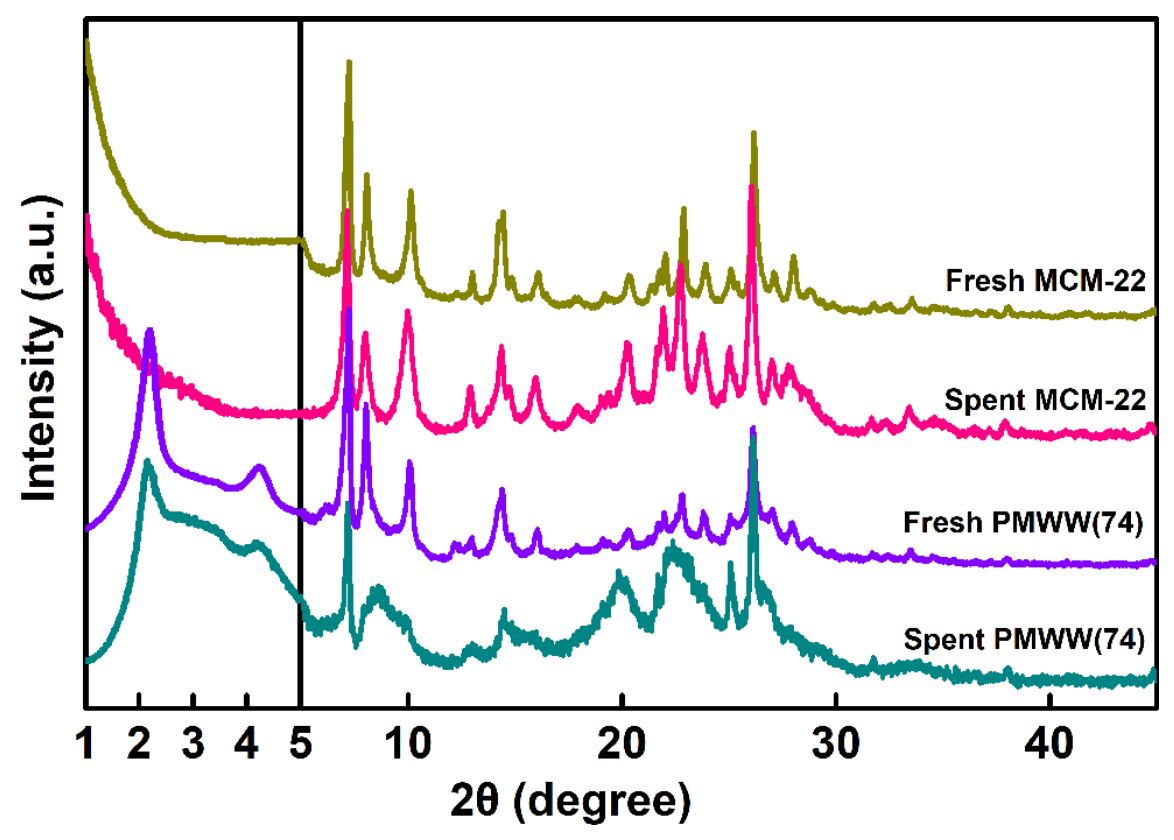

Figure. 12 XRD patterns of MCM-22 and PMWW(74) before and after 5 cycles. 


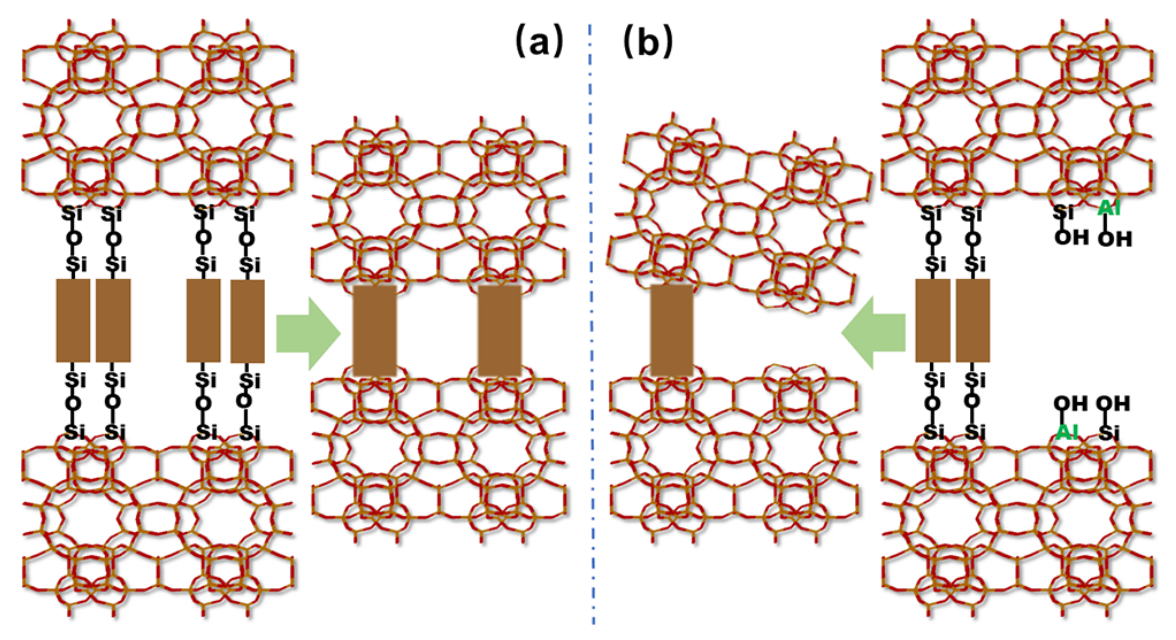

Scheme 1 The proposed arrangements of pillared MWW lamellar at (a) high and (b) low Si/Al ratios. 